\title{
Voltage instability identification with modified L-index using synchrophasor data
}

\author{
V. Vijaya Rama Raju1, K. H. Phani Shree², S.V.Jayarama Kumar ${ }^{3}$ \\ ${ }^{1}$ Electrical and Electronics Engineering Department, GRIET, Hyderabad, Kukatpally, Hyderabad, Telangana state, India \\ 2,3Electrical and Electronics Engineering Department, JNTUHCE, Kukatpally, Hyderabad, Telangana state, India
}

\begin{tabular}{|c|c|}
\hline Article Info & ABSTRACT \\
\hline Article history: & \multirow{10}{*}{$\begin{array}{l}\text { In the prevailing open-access environment, one of the limitations for power } \\
\text { exchanges has been voltage stability. The study of voltage stability } \\
\text { necessitates a complete network representation. In this paper, the advantage } \\
\text { of the dynamic behavior of generators is considered by incorporating } \\
\text { dynamic models for generators. It has been shown dynamic models resulted } \\
\text { in more accurate results compared to the conventional PV buses or ideal } \\
\text { voltage source models that are used in most of the voltage stability studies. } \\
\text { Moreover, the traditional L-index is augmented by incorporating real-time } \\
\text { and synchronized phasor data collected from the optimally located phasor } \\
\text { measurement units (PMU) in a wide-area measurement system (WAMS) to } \\
\text { estimate more accurate voltage stability margins. Simulation studies carried } \\
\text { out on IEEE 9-bus and IEEE 14-bus systems under various system } \\
\text { conditions. It has been demonstrated that the inclusion of dynamic models } \\
\text { and synchrophasor data from WAMS significantly improves the precision } \\
\text { with which voltage stability analysis results are obtained. }\end{array}$} \\
\hline Received May 20, 2021 & \\
\hline Revised Jul 28, 2021 & \\
\hline Accepted Aug 4, 2021 & \\
\hline Keywords: & \\
\hline L-index & \\
\hline Phasor measurement unit & \\
\hline Synchrophasor data & \\
\hline Voltage stability & \\
\hline Wide area monitoring system & \\
\hline
\end{tabular}

This is an open access article under the CC BY-SA license.

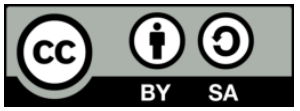

Corresponding Author:

V. Vijaya Rama Raju

Electrical and Electronics Engineering Department

GRIET, Kukatpally, Hyderabad, Telangana state, India

Email: vijayram_v@yahoo.com

\section{INTRODUCTION}

In the beginning, stability problems encountered in power system were mainly related to generator rotor angle stability and frequency stability problems, which are mainly generator driven [1]. Voltage instability was later established as a major threat to the operation of power systems, which is mainly load driven. Growing demand for power with constrained transmission capabilities, voltage stability and voltage collapse problems has gained the importance. In its most simplistic form, this can be explained as the system's inability to provide necessary reactive power or the system's excessive absorption of reactive power. Earlier it was associated with weak systems and long transmission lines, but now the load behaviour has a big effect on it. Voltage instability has been a significant concern to the activity of many power networks around the world in the last three decades. This has caused havoc on the economy and had important social implications. It has been one of the key causes of several worldwide blackouts like 1987's Tokyo blackout and 2003's United States, United Kingdom, Canada, Sweden, Italy and Denmark blackouts [2], [3]. In order to estimate the voltage instability, researchers have suggested many voltage stability indices, and a few have been used for voltage stability analysis in real time. They include traditional indices defined using minimum eigenvalue, P-V and P-Q curves [4], [5], continues power flow [6], singular value decomposition [7], sensitivity analysis methods [8], bifurcations theory [9], and L-index [10]. 
These studies mainly aim at determining the available margin between the present operating state with the voltage stability limit. Since the magnitudes of voltages alone fail to give good insight about the nearness to voltage stability limit, researchers proposed several voltage stability indices (VSIs), to monitor voltage stability. System operators can easily monitor these VSIs, which are scalar magnitudes to know the proximity to voltage stability limit. These indices were classified into two categories, VSIs defined using Jacobian matrix and VSIs defined using system variables. Voltage collapse point can be obtained using Jacobian matrix based indices, such as test function [11], [12], second order index [13], tangent vector [14] and V/V0 [15]. The drawback with these indices is high computational time. This will restrict their application for off-line studies. Whereas, system variable based indices such as L index, stability index (SI) [16], voltage collapse index (VCI) [17], Lmn index [18], LQP index [19], fast voltage stability index (FVSI) [20], voltage collapse point indicators (VCPI) [21], P-index [22], use the admittance matrix elements, bus voltages or power flow details. Voltage stability margin can be calculated in less time and these indices are more suitable for online monitoring applications [23]. Review and comparison of various VSIs proposed by the researchers [24], [25] in the last thee decades clearly shows the scope for investigation for the present study.

P. Kessel and H. Glavitsch has developed an indicator called L-index, which was a number that is scalar determined for every load bus representing the proximity to voltage instability using power flow solution. This was used for the detection and identification of vulnerable system states and to measure the gap between the present operating condition and the system's voltage stability collapse point. The scalar value of this index varies between 0 to 1 . Zero-representing the state of no-load and one representing voltage collapse state. Most vulnerable bus is the one, whose L-index value is near to 1 in the entire system. Hence, L-Index can be utilized to find the critical buses in the network as well as to assess the system state. Recent advancements in wide area measurements using phasor measurement units (PMU) [26] in contrast to the methods that has used loacal measurements [27]-[29] with optimal locations [30], [31] made the implementation of L-index more attractive. The reason for the identification of optimal locations being financial constraint posed by the size of the system, i.e., number of nodes present in the network [32].

The remaing part of this paper is devided into 4 parts and it is laid out as shown in. Section 2 delves into the mathematical modelling aspects of generators representing the dynamics of the generator for the dynamic simulations. The modified L-index incorporating generator dynamic model along with the use of synchrophasor data to evaluate it is expounded in Section 3. The efficacy of utilizing the dynamic model along with modified L-index with PMU data in voltage stability studies is substantiated in Section 4. Finally, Section 5 culminated in the conclusions drawn from the results.

\section{MODELLING OF GENERATORS}

Essential element of electrical energy generation in power systems is synchronous generator. Stability problem in power systems is mainly depends on the performance of these machines. Hence, understanding their characteristics and modelling of their dynamic performance are of fundamental importance. Mathematical model for synchronous generator was developed by using Park-Concordia model as per the schematic shown in Figure 1. To include the generator dynamic performance, automatic voltage regulator (AVR), and over excitation limiter (OXL) are considered along with the synchronous machine model. Synchronous machine is represented by $4^{\text {th }}$-order model. For voltage regulation of generator, IEEE standard Type-I AVR model is used.

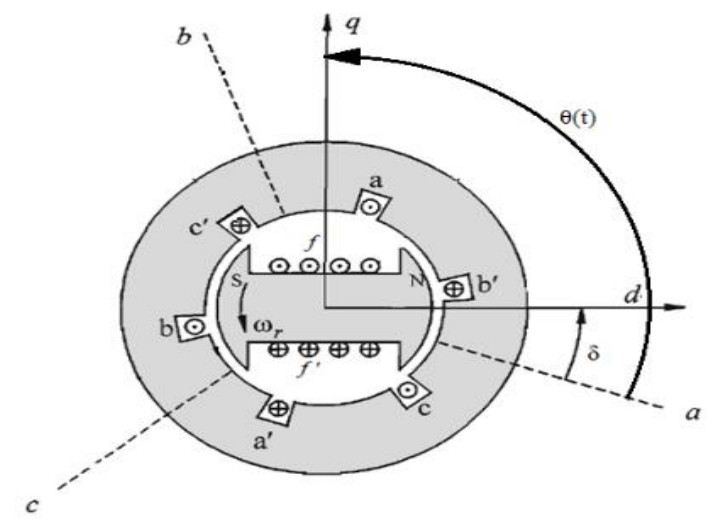

Figure 1. Schematic of synchronous machine 


\subsection{Generator equivalent model using synchrophasor data:}

The equivalent circuit for synchronous generator is considered as a voltage source representing the internal generated voltage in series with an impedance representing synchronous impedance comprising of synchronous reactance and armature resistance as shown in Figure 2. Normal practice followed for estimating generated voltage $E_{g}$ and series impedance $Z_{s}$ is by using Thevenin's equivalent method. These are estimated by taking the voltage at the terminals $v(t)$ and supply current $i(t)$ measurements at two consecutive time instants assuming the parameters remain constant during this period. Serious flaw in this approach is that, if the gap between the time instants is large, then the assumption is invalid. If the gap is too small, even the minute errors in the measurements results in large error in the parameter estimation. To overcome this problem, it is proposed in the present study to estimate these parameters using synchrophasor measurements obtained using PMUs only once, instead of using measurements at two different instants considering some of the machine parameters like resistances and reactances are known.

In the present research, $4^{\text {th }}$ order generator model along with AVR and OXL to include the generator dynamics is considered. For the fourth order model the direct axis (d -axis) and quadrature axis (q-axis) voltages $\left(V_{d} \& V_{q}\right)$ and currents $\left(I_{d} \& I_{q}\right)$ are associated by the following relations:

$$
\begin{aligned}
& 0=V_{q}+r_{a} I_{q}-E_{q}^{\prime}+\left(x_{d}^{\prime}-x_{l}\right) I_{d} \\
& 0=V_{d}+r_{a} I_{d}-E_{d}^{\prime}-\left(x_{q}^{\prime}-x_{l}\right) I_{q}
\end{aligned}
$$

Where $r_{a}$ represents armature resistance and $x_{l}$ is the leakage reactance.

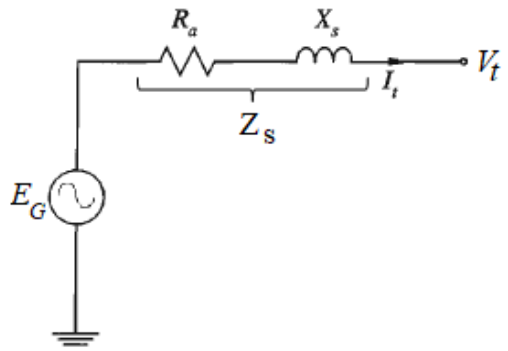

Figure 2. Thevenin's circuit for generator

From gnerator's Thevenin's circuit shown in Figure 2, synchronous impedance of the generator can be calculated by using (2):

$$
Z_{s}=\frac{E_{G}-V_{t}}{I_{t}}
$$

Where $E_{G}=\left(E_{d}^{\prime}+j E_{q}^{\prime}\right) e^{j\left(\delta-\frac{\pi}{2}\right)}, V_{t}=\left(V_{d}+j V_{q}\right) e^{j\left(\delta-\frac{\pi}{2}\right)}$ and $I_{t}=\left(I_{d}+j I_{q}\right) e^{j\left(\delta-\frac{\pi}{2}\right)}$.

Generated voltage can be calculated as shown in (3):

$$
E_{G}=V_{t}+Z_{s} I_{t}
$$

Thus, the values of $E_{G} \& Z_{S}$ that vary with system states can easily be obtained directly from the synchrophasor measurements $\left(V_{t} \& I_{t}\right)$ from the PMUs located at the generator terminals if the resistances and reactances of (1) are known.

\subsection{Generator model}

Fourth-order model is used in the present study for synchronous generator. This model was derived after making various simplifications to the traditional swing equation to an eight-order model considering field saturation while maintaining generator dynamics intact. Transient effects by the damping windings are considered, whereas the sub-transient effects leading to demagnetizing effects because of rotor position are ignored to simplify the model. Following assumptions are made to simplify the model:

$$
T_{d o}^{\prime \prime} \rightarrow 0, X_{d}^{\prime \prime} \rightarrow X_{d}^{\prime}, E_{q}^{\prime \prime} \rightarrow E_{q}^{\prime}
$$


In the present model $\mathrm{d}$-axis and q-axis inductances are modelled using lead-lag transfer functions. Hence, the system become fourth order with the state variables $\delta, \omega, E_{q}^{\prime}$ and $E_{d}^{\prime}$. Differential equations representing all the four state variables are as as shown in:

$$
\begin{aligned}
& \dot{\delta}=\Omega_{b}(\omega-1) \\
& M \dot{\omega}=\left(P_{m}-P_{e}-D(\omega-1)\right) \\
& T_{d o}^{\prime} \dot{E}_{q}^{\prime}=\left(-f_{s}\left(E_{q}^{\prime}\right)-\left(x_{d}-x_{d}^{\prime}\right) I_{d}+E_{f}\right) \\
& T_{q o}^{\prime} \dot{E}_{d}^{\prime}=\left(-E_{d}^{\prime}+\left(x_{q}-x_{q}^{\prime}\right) I_{q}\right)
\end{aligned}
$$

Electrical power $P_{e}$ is given by:

$$
P_{e}=\left(V_{q}+r_{a} I_{q}\right) I_{q}+\left(V_{d}+r_{a} I_{d}\right) I_{d}
$$

Where $\delta=\theta(t)-\omega_{s} t$ and $\theta(t)$ is the rotor angle, as indicated in Figure 1. ' $\omega$ ' is rotor speed in per unit, $\omega_{s}$ represents system's synchronous axis speed, $P_{m}, P_{e}$ are mechanical and electrical powers respectively, D-damping coefficient and M-mechanical starting time. $E^{\prime}$ refer to transient voltages behind transient reactance, $x, x^{\prime}$ are synchronous as well as transient reactances respecivily, $E_{f}$ is the exciter field voltage, and $T_{o}^{\prime}$ the open-circuit time constants. Subscripts $d \& q$ representing direct and quadrature axis quantities. Units of $\delta$ and $\omega_{s}$ are radian and radian/s, respectively. Variables $T_{d o}^{\prime}, T_{q o}^{\prime}$, and $\mathrm{M}$ are in seconds. All other parameters are p.u. values.

\section{MODIFIED L-INDEX FOR MULTI MACHINE SYSTEM}

Modelling of single machine system with Thevenin equivalent model using (3) is presented in section 2. For the multimachine system shown in Figure 3, similar analysis is performed to derive the modified L-index.

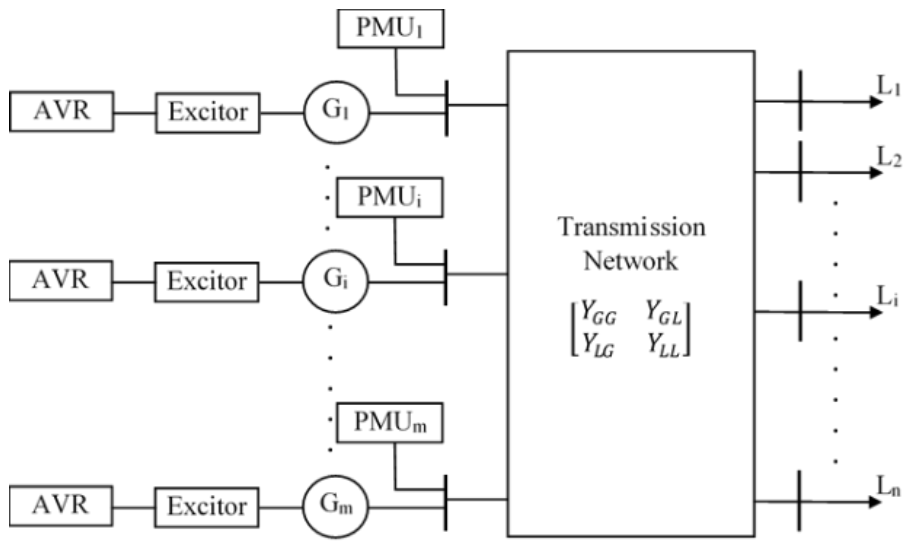

Figure 3. Multimachine power system with PMUs

Multimachine power system shown in Figure 3 consists of ' $m$ ' number of generators equipped with AVR and Exciter to take care the system dynamics and PMU for the synchronous phasor measurements of the terminal voltage and current to estimate the voltage stability. The multimachine system shown in the Figure 3 can be mathematically modelled using (7) considering the Thevenin's circuit for each generator.

$$
\left[\begin{array}{c}
I_{G} \\
0 \\
-I_{L}
\end{array}\right]=\left[Y_{\text {bus }}\right]\left[\begin{array}{l}
E_{G} \\
V_{T} \\
V_{L}
\end{array}\right]=\left[\begin{array}{lll}
Y_{G G} & Y_{G T} & Y_{G L} \\
Y_{T G} & Y_{T T} & Y_{T L} \\
Y_{L G} & Y_{L T} & Y_{L L}
\end{array}\right]\left[\begin{array}{c}
E_{G} \\
V_{T} \\
V_{L}
\end{array}\right]
$$

Where $V$ 's and I's correspond to the voltages and current injection phasors at various busses like generator internal, terminal and loads denoted by subscripts $G, T$ and $L$ respectively. $Y_{b u s}$ representing the 
admittance matrix. Sub matrix $\left[\begin{array}{ll}Y_{G G} & Y_{G L} \\ Y_{L G} & Y_{L L}\end{array}\right]$ represents the admittance matrix of the rest of the system existing between generators and loads. Other sub matrices $Y_{G T}, Y_{T G}, Y_{L T}, Y_{T L}$ are transfer admittance matrices between generator internal bus and load buses with the generator terminal buses. Since there is no direct connection between load buses and generator terminal buses sub matrices $Y_{L G} \& Y_{G L}$ become zero.

Eliminating $V_{T}$ from (7) we get

$$
\begin{aligned}
& I_{L}=\left(Y_{L T} Y_{T T}{ }^{-1} Y_{T G}\right) E_{G}-\left[Y_{L L}-\left(Y_{L T} Y_{T T}{ }^{-1} Y_{T L}\right)\right] V_{L} \\
& =Y_{L G}{ }^{\prime} E_{G}+Y_{L L}{ }^{\prime} V_{L}
\end{aligned}
$$

Where $Y_{L G}{ }^{\prime}=Y_{L T} Y_{T T}{ }^{-1} Y_{T G}$ and $Y_{L L}{ }^{\prime}=-\left[Y_{L L}-\left(Y_{L T} Y_{T T}{ }^{-1} Y_{T L}\right)\right]$.

Load buses voltages can be derived as

$$
V_{L}=-Y_{L L}^{-1} I_{L}-Y_{L L}^{-1} Y_{L T} V_{T}=F_{L G}{ }^{\prime} V_{T}-Z_{L L}{ }^{\prime} I_{L}
$$

Where $F_{L G}{ }^{\prime}=-Z_{L L}{ }^{\prime}\left(Y_{L G}-Y_{L T} Y_{T T}{ }^{-1} Y_{T G}\right)$ and $Z_{L L}{ }^{\prime}=-Y_{L L}{ }^{-1}$

Voltage at the $i^{\text {th }}$ load bus can be obtained using (10)

$$
V_{L i}=\sum_{j=1}^{n_{G}} F_{L G_{i j}}{ }^{\prime} V_{G_{j}}-\sum_{j=1}^{n_{L}} Z_{L L_{i j}}{ }^{\prime} I_{L_{j}}
$$

Where $n_{G}$ and $n_{L}$ are the number of generator and load buses.

Modified L-index corresponding to the voltage collapse condition is given by

$$
L_{j}=\left|1-\frac{\sum_{i=1}^{n_{G}} F_{j i}{ }^{\prime} V_{G_{j}}}{V_{j}}\right|
$$

To evaluate the value of L at every bus, voltage and current phasors need to be available at the central load dispatch centers to observe the voltage stability. Here, in this work it is proposed to utilize the synchrophasor data from the PMUs installed at the generator buses to get the accurate value of voltage stability margin. This will avoid the errors from state estimator when phasor data from energy management systems (EMS) is used and the problems because of desynchronized data when SCADA measurements are used. These L-index values may be distinct at different buses, as the computed values of $F_{j i}{ }^{\prime}$ are different. As the voltage at the $j^{\text {th }}$ bus moves towards the voltage stability limit the value of $L_{j}$ approach to 1.0. It means that bus is most stressed and leads to the instability condition. So, system operators can continuously monitor the available margin and identify the weak buses in the system and take necessary precautions. Since the power system can be subjected to voltage instability problem when any one of the buses reaches the limit, overall power system voltage stability can be identified by identifying the weakest bus among all the buses in the system i.e., identifying the bus with highest value of $L_{j}$. Hence, L-index for the entire power system can be determined by using (12)

$$
L=\max _{j \in n_{L}}\left(L_{j}\right)
$$

While evaluating the voltage stability index, the dynamic behaviour of synchronous machines is considered by including the AVR and OXL in the generator models, as well as synchrophasor voltage and current values are directly taken from the PMUs that are more exact. Hence, the value of modified L-index defined in (12) is more accurate compared with the traditional L-index.

\section{SIMULATION RESULTS AND DISCUSSION}

Voltage stability studies using synchrophasor data and dynamic generator models to validate the use of modified L-index performed on IEEE 9-bus and 14-bus systems. Power system analysis toolbox (PSAT), an open-source software developed by Federico Milano is used to conduct the dynamic simulation studies on the IEEE standard test systems. Performance of conventional L-index is compared with the modified L-index.

\subsection{Voltage stability with increase in loading}

To investigate the effect of equivalent generator model on the identification of voltage stability with phasor measurement readings, simulation studies with increased loading factor $(\lambda)$ are performed on IEEE 9- 
bus and 14-bus systems. Constant impedance model used for static voltage stability studies is considered to represent the loads. Newton raphson (NR) algorithm to solve the base case static load flow problem is considered. Modified L-index is calculated using the PMU data available at the respective buses. Voltage stability of the test systems is estimated using the proposed L-index by increasing the loading factor from the initial value at the base case to till the point where the system fails to converge. The loading factor is increased in increments and the modified L-index is calculated initially for the 9-bus system without considering the generator equivalent model, generators are considered as just PV buses. Figure 4 shows the variation of modified L-Index with the varying loading factors at the buses 4, 5, 6, 7, 8, and 9 other than the generator buses. It is noticed that the L-Index is increased linearly in the initial values with loading factor, as it approaches a value more than 2, L-index value increased exponentially, and load flow problem failed to converge when loading factor becomes 2.5. Bus number 5 is found to be the weakest bus among all other buses from the observations. Then the simulations on the 9-bus system are carried out by replacing the generator buses with equivalent generator models. Generators are represented using fourth order model as explained in section 2.2.

Where demagnetizing effect due to sub transients by the damper windings are neglected without ignoring the effect due to transients. The results are presented in the Figure 5. When the generator equivalent model is considered, it is observed that, the systems tend to lose its voltage stability well before the loading factor reaches a value 2. This clearly shows that the traditional PV bus model used for static voltage stability studies will not provide the actual loading limit where instability occurs. Similar studies are also studied on an IEEE 14-bus system. It is observed that, bus number 14 is the critical bus and voltage instability observed at $\lambda=4$ when generator bus model is not considered whereas it is well ahead i.e., $\lambda=1.7$ when generator equivalent model is considered as shown in Figures 6 and 7 respectively. Continuation power flow method is used to determine the critical loading point or voltage collapse point.

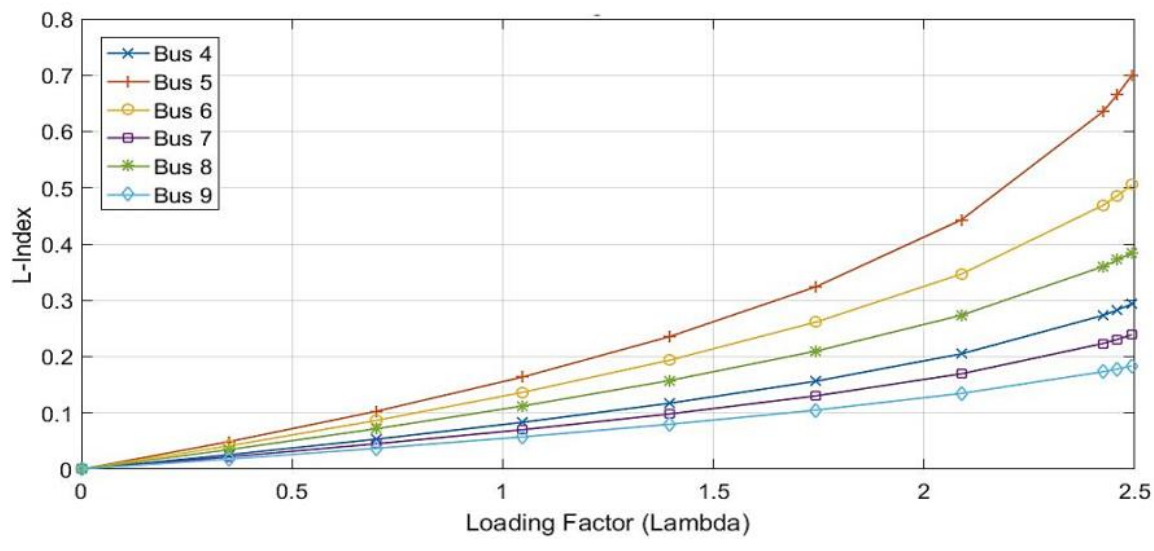

Figure 4. Variation of modified L-index with loading factor for IEEE 9-bus system: without considering generator equivalent model

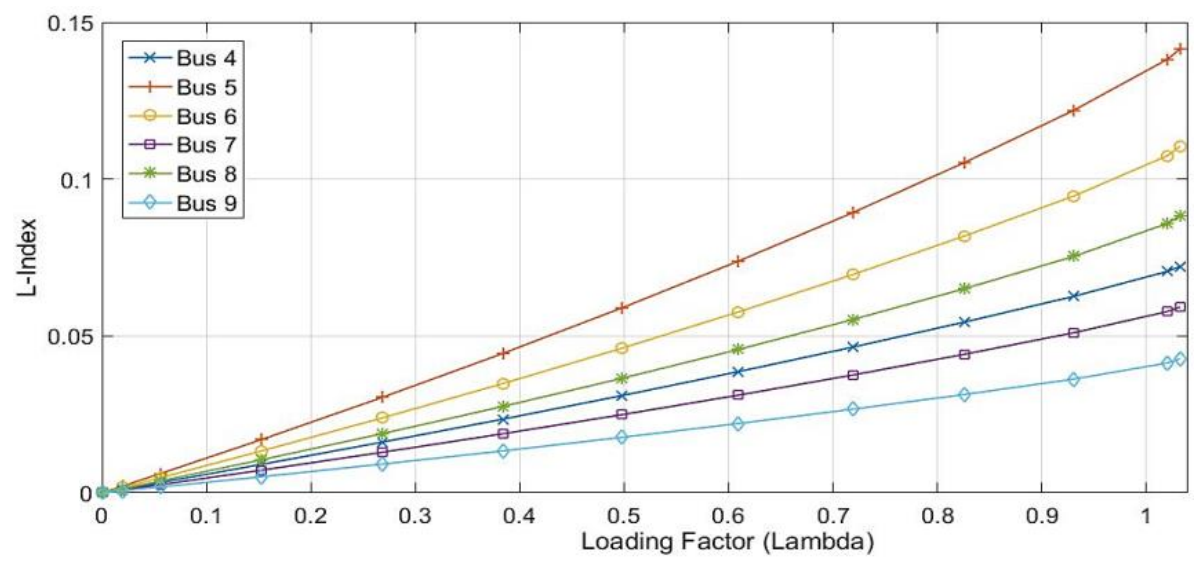

Figure 5. Variation of modified L-index with loading factor for IEEE 9-bus system: with considering generator equivalent model 


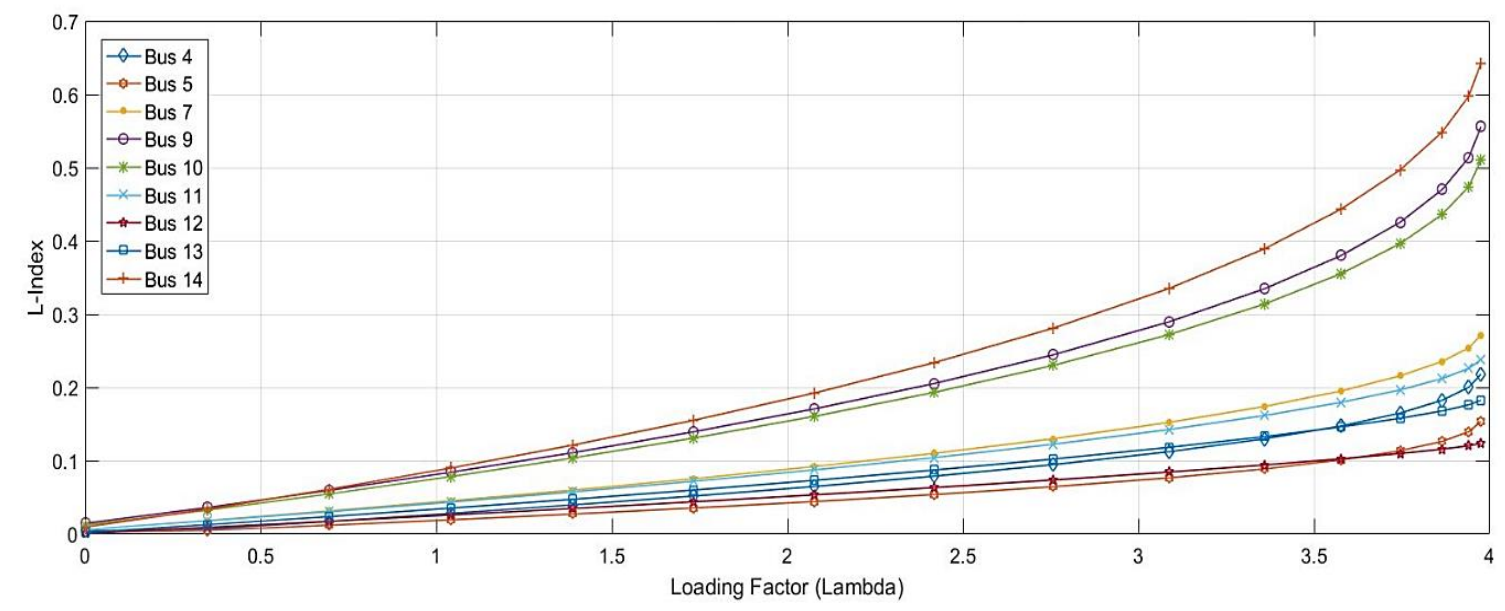

Figure 6. Variation of modified L-index with loading factor for IEEE 14-bus system: without considering generator equivalent model

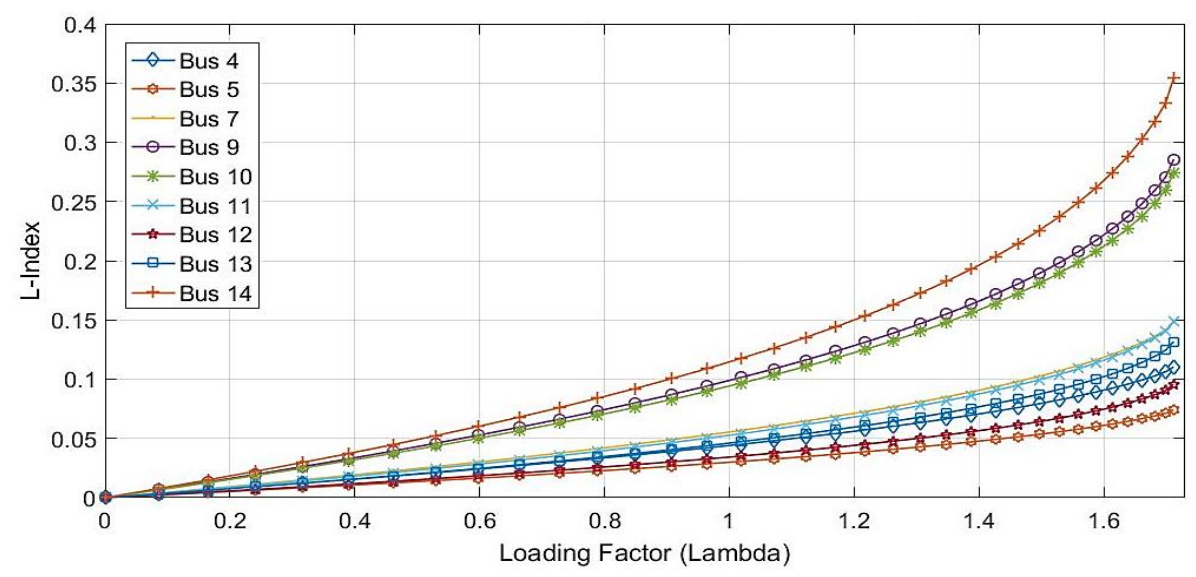

Figure 7. Variation of modified L-Index with loading factor for IEEE 14-bus system: with considering generator equivalent model

\subsection{Impact of line outage on voltage stability}

To understand the performance of modified L-index with PMU measurements during the dynamic operating conditions, system studies are performed on IEEE 14-bus system with line outage. Test system consisting of 16 lines, 4 transformers, 5 generators equipped with automatic voltage regulators (AVR) and 11 loads along with PMUs located at the optimum places with full system observability is given in Figure 8 .

Contingency is created by removing the line between bus 2 and bus 4 carrying a real power of 785.2MW and reactive power of 50.26 MVar at $1 \mathrm{sec}$ instant and it is considered as a permanent fault. Base case data is obtained by using NR load flow algorithm. Time domain analysis with the above contingency is performed using PSAT software tool. Time domain results from PSAT are used to estimate the voltage stability using modified L-Index. As bus number 14 is identified as the critical bus by the modified L-Index in the previous section (4.1), comparison between the traditional L-Index and modified L-Index is presented in Figure 9. Due to the contingency in the line between 2 and 4 buses, the system moved to voltage instability at time $21.54 \mathrm{sec}$. The modified L- index considering the generator equivalent model and AVR with PMU measurements could be able to trace the voltage dynamics of the system effectively. A sharp rise in the modified L-index (represented by L1) is observed at the voltage collapse point. It has reached to 1.0 p.u. in 21.54 seconds for bus number 14. Whereas the traditional L-index (represented by L) could not identify the voltage instability point as shown on Figure 9. Voltage collapse is also evident from the Figure 10 where variation of voltage magnitude with time at Bus 14 is shown. Similar observations are made at other buses especially the buses nearer to the bus number 14, such as bus number 9, 10, and 13 . 


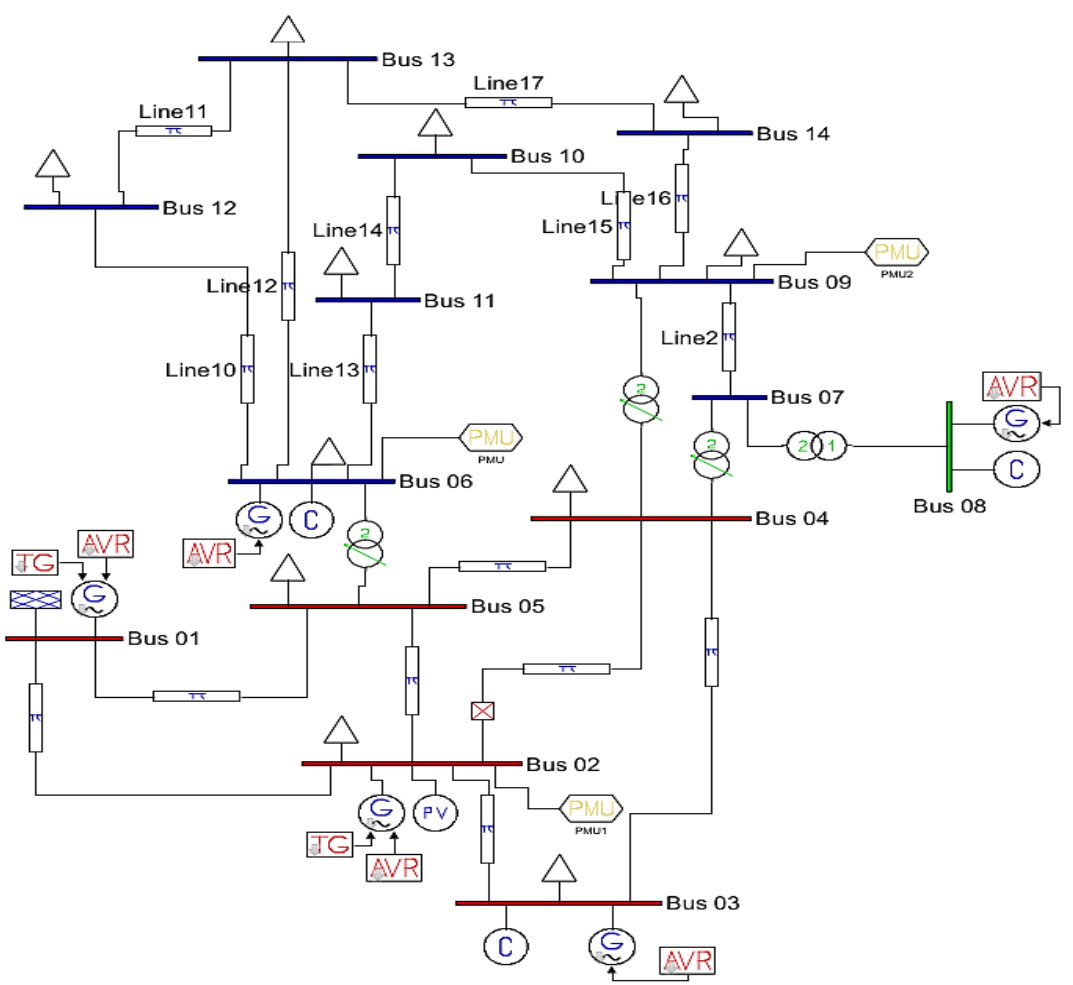

Figure 8. IEEE 14 bus system with synchronous generator dynamic model and PMU

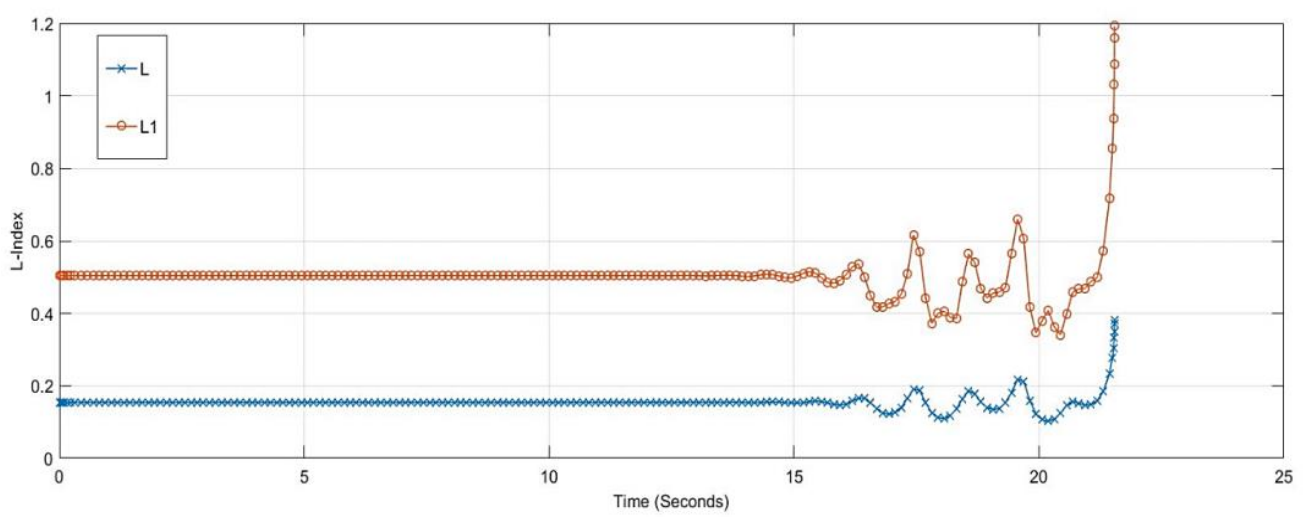

Figure 9. Comparison between modified L-index (L1) and L-index (L) under line outage contingency

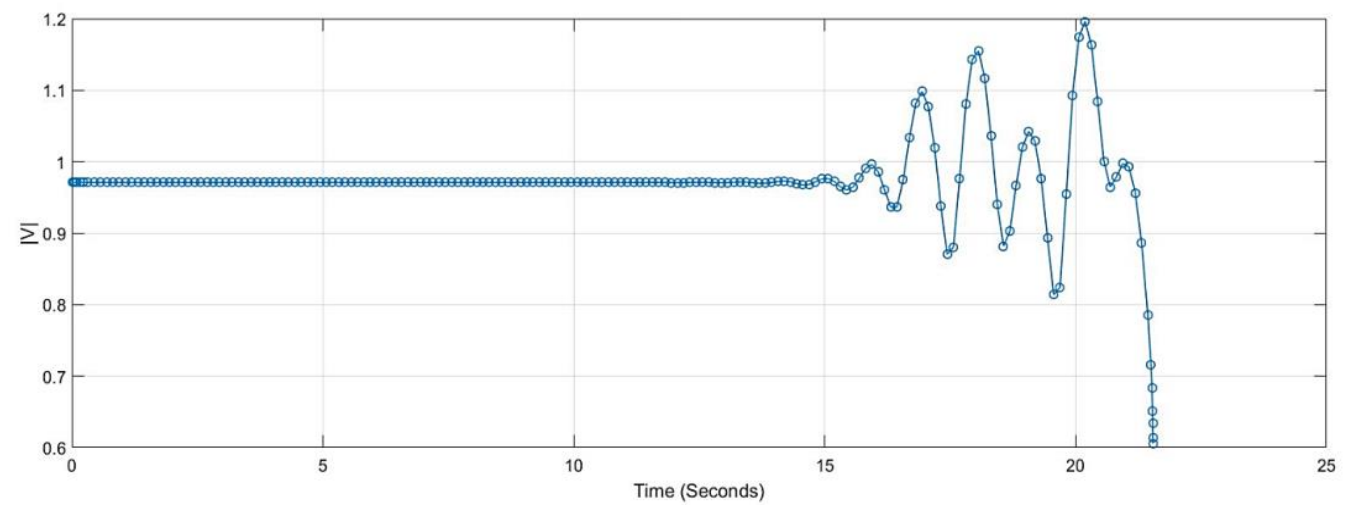

Figure 10. Variation of voltage magnitude with time at bus 14 


\section{CONCLUSION}

This paper presents a modified L-index that incorporates a generator equivalent model to identify voltage instability using synchrophasor data from phasor measurement units. The time-varying impedances and internal voltages derived from synchrophasor measurements are directly used to integrate dynamic performance of generators. The modified voltage stability index is proved to be effective compared with the traditional L-index in identifying potentially weak buses and the voltage instability condition well ahead. The index value approaches a value 1.0 whenever the voltage instability condition is reached. Data from the PMUs located at the generator and load buses is incorporated directly to evaluate the L-Index rather than calculating it using the admittance matrix and current measurements. This has made it easier to use this algorithm in online applications.

\section{REFERENCES}

[1] P. Kundur et al., "Definition and classification of power system stability IEEE/CIGRE joint task force on stability terms and definitions," in IEEE Transactions on Power Systems, vol. 19, no. 3, pp. 1387-1401, Aug. 2004, doi: 10.1109/TPWRS.2004.825981.

[2] T. Ohno and S. Imai, "The 1987 Tokyo Blackout," 2006 IEEE PES Power Systems Conference and Exposition, 2006, pp. 314-318, doi: 10.1109/PSCE.2006.296325.

[3] "Final Report on the August 14, 2003 Blackout in the United States and Canada: Causes and Recommendations," 2021, [Online]. Available: https://www.osti.gov/etdeweb/biblio/20461178 (accessed on 10 Apr. 2021).

[4] C. W. Taylor, "Power system voltage stability", EPRI power system engineering series, McGraw-Hill publications, 1993.

[5] V. Ajjarapu and C. Christy, "The continuation power flow: a tool for steady state voltage stability analysis," in IEEE Transactions on Power Systems, vol. 7, no. 1, pp. 416-423, Feb. 1992, doi: 10.1109/59.141737.

[6] B. Gao, G. K. Morison and P. Kundur, "Voltage stability evaluation using modal analysis," in IEEE Transactions on Power Systems, vol. 7, no. 4, pp. 1529-1542, Nov. 1992, doi: 10.1109/59.207377.

[7] P. Lof, G. Andersson and D. J. Hill, "Voltage stability indices for stressed power systems," in IEEE Transactions on Power Systems, vol. 8, no. 1, pp. 326-335, Feb. 1993, doi: 10.1109/59.221224.

[8] T. J. Overbye and C. L. DeMarco, "Improved techniques for power system voltage stability assessment using energy methods," in IEEE Transactions on Power Systems, vol. 6, no. 4, pp. 1446-1452, Nov. 1991, doi: $10.1109 / 59.116988$.

[9] V. Ajjarapu and C. Christy, "The continuation power flow: a tool for steady state voltage stability analysis," in IEEE Transactions on Power Systems, vol. 7, no. 1, pp. 416-423, Feb. 1992, doi: 10.1109/59.141737.

[10] P. Kessel and H. Glavitsch, "Estimating the Voltage Stability of a Power System," in IEEE Transactions on Power Delivery, vol. 1, no. 3, pp. 346-354, July 1986, doi: 10.1109/TPWRD.1986.4308013.

[11] Hsiao-Dong Chiang and R. Jean-Jumeau, "Toward a practical performance index for predicting voltage collapse in electric power systems," in IEEE Transactions on Power Systems, vol. 10, no. 2, pp. 584-592, May 1995, doi: $10.1109 / 59.387892$.

[12] C. A. Canizares, A. C. Z. De Souza and V. H. Quintana, "Comparison of performance indices for detection of proximity to voltage collapse," in IEEE Transactions on Power Systems, vol. 11, no. 3, pp. 1441-1450, Aug. 1996, doi: $10.1109 / 59.535685$.

[13] A. Berizzi, P. Finazzi, D. Dosi, P. Marannino and S. Corsi, "First and second order methods for voltage collapse assessment and security enhancement," in IEEE Transactions on Power Systems, vol. 13, no. 2, pp. 543-551, May 1998, doi: 10.1109/59.667380.

[14] A. C. Z. de Souza, C. A. Canizares and V. H. Quintana, "New techniques to speed up voltage collapse computations using tangent vectors," in IEEE Transactions on Power Systems, vol. 12, no. 3, pp. 1380-1387, Aug. 1997, doi: 10.1109/59.630485.

[15] N. D. Hatziargyriou and T. Van Cutsem, "Indices for predicting voltage collapse including dynamic phenomena," in International Conference on Large High Voltage Electric Systems, vol. 91, 1994.

[16] M. Chakravorty and D. Das "Voltage stability analysis of radial distribution networks" International Journal of Electrical Power \& Energy System, vol. 23, pp. 129-135, 2012, doi: 10.1016/S0142-0615(00)00040-5.

[17] M. H. Haque, "Use of local information to determine the distance to voltage collapse," 2007 International Power Engineering Conference (IPEC 2007), 2007, pp. 407-412.

[18] M. Moghavemmi, F. M. Omar, "Technique for contingency monitoring and voltage collapse prediction", IET Proceedings - Generation Transmission and Distribution, vol.145, no. 6, pp. 634-640, November 1998, doi: 10.1049/ip-gtd:19982355.

[19] A. Mohamed, G. B. Jasmon and S. Yusoff, “A static voltage collapse indicator using line stability factors”, Journal of industrial technology, vool. 7, no. 1, pp. 73-85, 1989.

[20] I. Musirin and T. K. Abdul Rahman, "Novel fast voltage stability index (FVSI) for voltage stability analysis in power transmission system," Student Conference on Research and Development, 2002, pp. 265-268, doi: 10.1109/SCORED.2002.1033108.

[21] M. Moghavvemi and O. Faruque, "Real-Time Contingency Evaluation and Ranking Technique," IET Proceedings Generation Transmission and Distribution, vol. 145, no.5, pp. 517-524, September 1998, doi: 10.1049/ipgtd:19982179. 
[22] M. Kamel, A. A. Karrar and A. H. Eltom, "Development and Application of a New Voltage Stability Index for OnLine Monitoring and Shedding," in IEEE Transactions on Power Systems, vol. 33, no. 2, pp. 1231-1241, March 2018, doi: 10.1109/TPWRS.2017.2722984.

[23] P. Sahu and M. K. Verma, "Online monitoring of voltage stability margin using PMU measurements," International Journal of Electrical and Computer Engineering, vol. 10, no. 2, pp. 1156-1168, 2020, doi: 10.11591/ijece.v10i2.pp1156-1168.

[24] S. S. Danish, T. Senjyu, S. M. S. Danish, N. R. Sabory, K. Narayanan, and P. Mandal, "A recap on volatge stability indices in the past three decades," Energies, vol. 12, no. 8, p. 1544, 2019, doi: 10.3390/en12081544.

[25] H. Zaheb, et al., "A contemporary novel classification of voltage stability indices," Applied Sciences, vol. 10, no. 5, p. 1639, 2020, doi: 10.3390/app10051639.

[26] A. G. Phadke, "Synchronized phasor measurements in power systems," in IEEE Computer Applications in Power, vol. 6, no. 2, pp. 10-15, April 1993, doi: 10.1109/67.207465.

[27] K. Vu, M. M. Begovic, D. Novosel and M. M. Saha, "Use of local measurements to estimate voltage-stability margin," in IEEE Transactions on Power Systems, vol. 14, no. 3, pp. 1029-1035, Aug. 1999, doi: $10.1109 / 59.780916$.

[28] M. Zima, M. Larsson, P. Korba, C. Rehtanz and G. Andersson, "Design Aspects for Wide-Area Monitoring and Control Systems," in Proceedings of the IEEE, vol. 93, no. 5, pp. 980-996, May 2005, doi: 10.1109/JPROC.2005.846336.

[29] W. Li, Y. Wang and T. Chen, "Investigation on the thevenin equivalent parameters for online estimation of maximum power transfer limits", IET Generation Transmission \& Distribution, vol. 4, no. 10, pp. 1180-1187, Oct. 2010, doi: 10.1049/iet-gtd.2010.0342.

[30] V. V. R. Raju and S. V. J. Kumar, "An optimal PMU placement method for power system observability," 2016 IEEE Power and Energy Conference at Illinois (PECI), 2016, pp. 1-5, doi: 10.1109/PECI.2016.7459248.

[31] K. Khalid, A. A. Inrahim, N. A. M. Kamari, and M. H. M. Zaman, "An optimal placement of phasor measurement unit using new sensitivity indices," Bulletin of Electrical Engineering and Informatics, vol. 10, no. 1, pp. 31-38, 2021, doi: 10.11591/eei.v10i1.2499.

[32] M. A. A. Alasali, M. Zuhaib, and M. Rihan, "An investigation on the application and challenges for wide area monitoring and control in smart grid," Bulletin of Electrical Engineering and Informatics, vol. 10, no. 2, pp. 580587, 2020, doi: 10.11591/eei.v10i2.2767.

\section{BIOGRAPHIES OF AUTHORS}

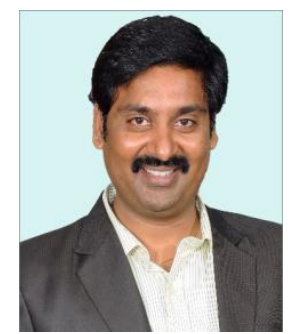

V. Vijaya Rama Raju got his master's degree from National Institute of Technology Warangal (NITW) in the year 2001 with Power Systems specialization. During his masters program he has developed various control algorithms for FACTS devices while working in Electrical Research and Development Association (ERDA), Baroda. He is currently a Senior member of IEEE, recognized as Chartered Engineer (India) by IE (India) and also a Fellow member of Institution of Engineers India. Currently pursuing $\mathrm{Ph} . \mathrm{D}$ in the area of synchrophasor technology and published several papers in international conferecnes and journals. His research areas are Smart Grids and Renewable Energy systems. At present he is working as Associate Professor in the department of Electrical and Electronics Engineering, GRIET, Hyderabad, India.

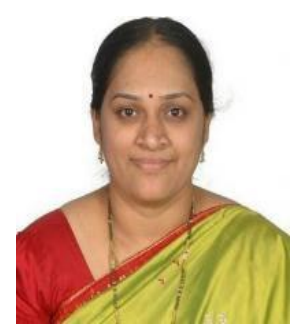

K. H. Phani shree pursued her Master's Degree in Power systems from NIT Trichurapalli and Doctoral Degree from JNTU Hderabad. She has 18 years of experience in both teaching and research. For her constributions in power electronics she was awarded with Engineering Impact Award by National Instruments in the year 2016. She is a Member of IEEE \& ISTE. Established Research Lab in EEE department of JNTU. Her research findings were published in 12 jounals. She has guided 25 PG and 20 UG Projects. Currently guiding 3 Ph.D scholors. At present, she is working as Associate Professor in EEE dept. of JNTUH College of Engineering Hyderabad. Her research areas are Power Electronics and Drives, FACTS, and Renewable energy systems.

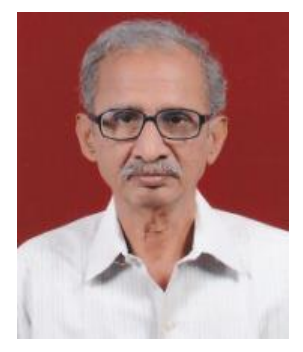

S. V. Jayaram Kumar pursuied his master's degree in Electrical Engineering from Andhra University, Vishakapatnam, India in the year 1979. He has received Doctorol degree in Electrical Engineering from IIT, Kanpur, in the year 2000. He has retiered as Professor from Jawaharlal Nehru Technological University Hyderabad with more tha 30 years of teaching and research experience. His research areas are Power System Dynamics and FACTS controllers. 